\title{
Da Acádia à Colônia São Lourenço: a versão pomerana de uma canção cajun ${ }^{1}$
}

\section{From Acadia to São Lourenço Colony: a Pomeranian version of a

\author{
Cajun song
}

Danilo Kuhn²

Submetido em 9 de março e aprovado em 25 de abril de 2020.

Resumo: Através da análise da canção Álas folóra ${ }^{3}$, da banda Musical Boa Esperança, este artigo objetiva abordar o processo de hibridismo musical fruto da recriação de tradições exógenas dentro de uma tradição endógena: enquanto a referida canção está inserida em um contexto musical pomerano, na área de São Lourenço do Sul, região da Serra dos Tapes, sul do estado do Rio Grande do Sul, Brasil, Jambalaya (on the Bayou), da qual a primeira é uma versão, advém da música country estadunidense e, ainda, contém elementos musicais da cultura cajun (descendentes de colonizadores franceses da Acádia, região do atual Canadá, posteriormente emigrados para o estado norte-americano da Luisiana). Este percurso cultural será analisado ao longo do texto à luz dos conceitos de hibridismo (CANCLINI, 2011), de fragmentação cultural (HALL 2002; 2011) e memória cultural (ASSMANN; CZAPLICKA, 1995). Conclui-se que o referido percurso reforça a visão contemporânea que questiona noções essencialistas acerca das identidades culturais e desconstrói entidades culturais fechadas.

Palavras-chave: Cajuns. Pomeranos. Canadá. Música. Hibridismo. Memória cultural.

Abstract: Through the analysis of the Alas folóra song, from the band Musical Boa Esperança, this paper aims to address the musical hybridity process recreated from exogenous traditions within an endogenous tradition: while the referred song is inserted in a Pomeranian musical context, in the area of São Lourenço do Sul, Serra dos Tapes region, South of Rio Grande do Sul state, southern Brazil, Jambalaya (on the Bayou), of which the first is a version, comes from the American country music and also contains musical elements of the Cajun culture (descendants of Acadia French colonists, region of present-day Canada, later emigrated to the Louisiana North American state). This cultural route will be analyzed throughout the text in the light of hybridism. (CANCLINI, 2011), cultural fragmentation (HALL 2002; 2011) and cultural memory (ASSMANN; CZAPLICKA, 1995) concepts. It is concluded that the referred route reinforces the contemporary vision that questions essentialist notions about cultural identities and deconstructs closed cultural entities.

Keywords: Cajuns. Pomeranians. Canada. Music. Hybridism. Cultural memory. 
$2 \quad \mid$ Danilo Kuhn

\section{Introdução}

Jambalaya (On the Bayou) é uma canção gravada em 1952 pelo cantor country estadunidense Hank Williams (1923-1953) que gerou muitas versões e alcançou popularidade em vários gêneros musicais (ESCOTT, 2004). Seu título faz menção a um prato da cozinha cajun - grupo étnico formado por descendentes de colonizadores franceses estabelecidos na Acádia, uma região do nordeste da América do Norte, que se encontra em território do atual Canadá (CARON, 2015, p. 5) -, uma espécie de paella de influência multicultural, bastante apreciada no estado da Luisiana, Estados Unidos (SIGAL, 2007, p. 102), onde cajuns se assentaram após sua expulsão da Acádia no século XVIII (C. A. BRASSEAUX, 1985, p. 126). Seu sucesso levou à criação de inúmeras versões em vários países, inclusive no Brasil.

Entretanto, o foco deste trabalho, para além de uma digressão histórico-cultural em direção às origens de Jambalaya, é a análise de uma versão em específico, criada em 2017 no estado do Rio Grande do Sul, Brasil, pelo conjunto pomerano Musical Boa Esperança, intitulada Álas folóra. A letra, em pomerano, versa sobre a crise no país e os problemas rurais oriundos desta, e o arranjo musical também foi "pomeranizado", utilizando-se de instrumentos tradicionais.

A primeira seção do artigo aborda aspectos históricos da Acádia, região do atual Canadá onde se estabeleceram os imigrantes cajuns oriundos da França no século XVII, cultura da qual se originou a canção Le garçon negligent (The Guidry Brothers), precursora de Jambalaya (on the Bayou), já em solo estadunidense; da Luisiana, estado dos Estados Unidos onde os cajuns se alocaram após sua expulsão da Acádia no século XVIII. Nesta seção trata-se ainda da Pomerânia, região europeia (entre Alemanha e Polônia), da qual emigraram os pomeranos na metade do século XIX para o Brasil. Finalmente, fala-se também da colônia São Lourenço, fundada em 1858 na região da Serra dos Tapes, sul do estado do Rio Grande do Sul, sul do Brasil, formada majoritariamente por pomeranos, comunidade a que o Musical Boa Esperança pertence.

Já a segunda seção se refere aos conceitos de hibridismo (CANCLINI, 2011) e memória cultural (ASSMANN; CZAPLICKA, 1995), além da abordagem de Hall (2002; 2011) acerca da fragmentação cultural, os quais auxiliam a descortinar a intrincada trama 
do percurso cultural percorrido por Le garçon negligent até Alás folóra. A terceira e última seção, enfim, analisa a canção inicial e a canção final do percurso delineado, perscrutando os meandros culturais de ambas.

Espera-se, com este artigo, elucidar uma trajetória um tanto improvável e complexa, onde uma canção cajun francesa do início do século XX se transforma em uma canção em pomerano ao sul do sul do Brasil na segunda década do século XXI, passando por inúmeros processos híbridos, memoriais e identitários.

\section{Da Acádia à colônia São Lourenço}

Segundo Caroline-Isabelle Caron (2015, p. 4), já no final do século XVI a região mais conhecida como Canadá Atlântico atraiu o interesse da França, mas, devido ao conhecimento geográfico limitado e à intensa competição pela pesca e pelo comércio de peles com indígenas locais, poucos colonos lá se instalaram antes da década de 1630 . Em 1605 a colônia da Acádia nasceu oficialmente com a construção do forte de PortRoyal, capital acadiana entre 1605 e 1710, atual Annapolis Royal, província da Nova Escócia, Canadá. Após difíceis começos e uma breve aquisição britânica de 1629 a 1632, o novo governador, Isaac de Razilly, foi o primeiro a recrutar colonos para um assentamento permanente na Acádia. Assim, em 08 de setembro de 1632, na cidade de LaHave, instalou-se o primeiro assentamento permanente de colonos franceses na região, um grupo de cerca de trezentos homens, marinheiros, soldados, jornaleiros (diaristas) e artesãos, e cerca de quinze famílias.

No entanto, tropas da Nova Inglaterra tomaram Port-Royal em outubro de 1710. A partir de então, Massachusetts tomou o controle político da Acádia em nome da GrãBretanha. Depois da conquista, que foi selada pelo Tratado de Utrecht em 1713, a Acádia desapareceu como unidade política. A França, no entanto, manteve a Nova França e as ilhas do Golfo de Saint Lawrence. As novas autoridades coloniais adquiriram a Acádia, que renomearam de Nova Escócia, enquanto as tropas francesas recuaram para a atual Nova Brunswick. De acordo com os termos do tratado, a França devia entregar a Acádia à Grã-Bretanha, "na sua totalidade dentro das suas antigas fronteiras" (CARON, 2015, p. 7). No entanto, o Tratado não especificou o que eram essas fronteiras anteriores. Para 
a França, elas estavam limitadas à península da Nova Escócia. Para a Grã-Bretanha, a Acádia também se estendia à Nova Brunswick. Essa diferença de opinião, entre outros fatores, levou à Guerra dos Sete Anos quatro décadas depois.

Em 1754, quando as hostilidades entraram em erupção entre a Nova França e a Nova Inglaterra (dois anos antes de França e Inglaterra declararem oficialmente guerra uma contra a outra), o tenente-governador Charles Lawrence convenceu-se de que os acadianos estavam prestes a tomar as armas contra os ingleses, o que veio a confirmar-se na batalha de Beauséjour (03 a 06 de julho de 1755). Em 28 de julho de 1755, Lawrence decidiu pôr fim ao problema, expulsando os acadianos da região. Embora essa decisão política e militar estivesse de acordo com as táticas militares do século XVIII, seu escopo era sem precedentes (CARON, 2015).

Em seu panorama histórico, Caron (2015) esclarece que os governos das Treze Colônias (que dariam origem aos Estados Unidos) não foram informados sobre a decisão final de Lawrence. Por terem ficado despreparados para lidar com centenas de acadianos - a maioria deles doente e sem dinheiro -, eles os receberam com grande relutância e suspeita. A maneira como os acadianos foram tratados variou de colônia a colônia: foram aceitos como servos contratados (Maryland e Pensilvânia); tiveram seus filhos alocados com famílias protestantes (Massachusetts); trabalharam juntamente com escravos africanos nas plantações (Geórgia); passaram o inverno a bordo dos navios que os carregaram, em péssimas condições (Virgínia); não tiveram seu desembarque permitido (Carolina do Norte); etc. Os sobreviventes foram deportados para a Inglaterra e colocados em campos de prisioneiros nas cidades portuárias de Falmouth, Portsmouth e Bristol. São os filhos e netos desses prisioneiros, transferidos para a França em 1765, que viajaram para a Luisiana em 1785 para tornarem-se os cajuns de hoje (CARON, 2015, p. 11).

De acordo com McKernan (2010), nos dias de hoje a cultura cajun domina 22 das 56 paróquias da Louisiana, todas localizadas a sudoeste, caracterizada por ser uma cultura rural, atrelada a pequenas cidades, cujos membros atuam majoritariamente como caçadores, pescadores e agricultores. Segundo o autor, os cajuns foram isolados 
da influência da cultura moderna até a Segunda Guerra Mundial, mas, no entanto, aos poucos os efeitos do rádio, do cinema e da televisão minaram o estilo de vida cajun com resultados ruins para seus valores tradicionais - especialmente para a linguagem cajun. Independentemente disto, os cajuns rejeitaram amplamente uma "americanização" profunda, pois, conforme McKernan (2010), “a difusa influência da cultura e da sociedade americanas pode ter reforçado sentimentos de solidariedade étnica e identidade cultural entre os cajuns, em vez de reduzi-la" (MCKERNAN, 2010, p. 2).

Para o autor, a preservação da cultura cajun da Louisiana foi assistida, dentre outros fatores, pela Igreja Católica, por fortes laços familiares, e festivais que celebravam a comunidade, sua culinária e música distintas. Além disso, o renascimento de sua consciência identitária na década de 1960 resultou em políticas públicas que promoveram a autoestima cultural cajun.

De acordo com McKernan (2010), o conceito de cultura como um modo de vida é um conceito complexo e intrincado. Normalmente, o significado da cultura envolve preocupações estéticas, como arte, música, dança, escultura e artes decorativas. No entanto, a cultura também tem um lado antropológico, referindo-se à totalidade de padrões, crenças e instituições transmitidos socialmente e aos costumes, realizações, produções, perspectivas de uma sociedade ou grupo. A cultura cajun, segundo McKernan (2010), está intimamente ligada ao senso antropológico do termo; em outras palavras, é cultura como um modo de vida.

De acordo com este autor, o aspecto mais importante deste senso de cultura é que ele permite uma base para a expressão de crenças sobre identidade compartilhada. Pessoas que são e fizeram parte de uma cultura mantêm certas coisas em comum e olham o mundo de uma perspectiva compartilhada. Estas preocupações comunais se manifestam como tradições e expressões únicas. Para os cajuns, a cultura apresenta a oportunidade de identificação com base no senso de identidade pessoal compartilhada.

Conforme Jordan (1985), a concepção de cultura como modo de vida abarca um papel importante na formação dos grandes quadros de valores que determinam tradições comunitárias e proximidade social e autoestima individual. Uma cultura que é um modo de vida geralmente é baseada no território, orientada para a tradição, abrangente 
e reconhecida como tal pela população local e forasteiros. Isto não se restringe a uma questão de interesses pessoais, diversão ou entretenimento. O modo de vida cajun é identificável através de seus rituais compartilhados e padrões expressivos e unificados, como costumes tradicionais, carnaval, comida, música, religião, história comunitária e uma identificável pátria regional. Tais valores profundamente arraigados mantêm a união e constituem um amálgama social.

\section{$* * *$}

Por seu turno, a colônia São Lourenço, situada na Serra dos Tapes ${ }^{4}$, foi uma colônia particular germânica, a mais ao sul do Brasil, fundada em 1858, formada majoritariamente por imigrantes pomeranos (PODEWILS, 2011, p. 15). De acordo com Schröder (2003), a maioria pomerana deveu-se à sua capacidade agrícola: “Após a chegada de mais de 115 pessoas no ano de 1858 , os anos posteriores trouxeram elementos mais apropriados: trabalhadores rurais da Pomerânia" (SCHRÖDER, 2003, p. 123).

A Pomerânia é uma região de amplas e férteis planícies situada na costa do mar Báltico, no nordeste da Alemanha e no noroeste da Polônia, que passou por constantes invasões e disputas de território ao longo da história, tendo sido dividida entre os referidos países após a Segunda Guerra Mundial.

De acordo com pesquisas recentes (WILLE, 2011; HAMMES, 2010, v. 1-4; COSTA, 2007; SALAMONI, 1995), os pomeranos têm ascendência eslava, do povo wende, os quais eram pagãos que tinham como divindade principal um deus de três cabeças chamado Triglav. O nome da região da Pomerânia - em alemão, Pommern advém do termo eslavo Po-Morje, que significa terra ao longo do mar. Os pomeranos foram cristianizados a partir do ano de 1124 por Otto de Bamberg, quando foi destruído o templo dedicado ao deus Triglav na cidade de Estetino ${ }^{5}$, e, posteriormente, germanizados a partir de 1400, quando progressivamente a língua alemã se impõe na Pomerânia.

A sobrevivência do idioma pomerano na região tem sido alvo de estudos $\operatorname{acadêmicos}^{6}$, mas, no tocante a este artigo, importa salientar que, apesar de esforços esparsos de algumas escolas, igrejas, associações pomeranas e algumas iniciativas de prefeituras, são poucos os incentivos extracomunitários à preservação desta língua. 
Contudo, o pomerano continua sendo falado por grande parcela da comunidade, utilizado em festas comunais, no dia-a-dia em estabelecimentos comerciais e em outras situações sociais.

Para além, conforme Ferreira e Heiden (2009), os usos do passado em São Lourenço do Sul (e na Serra dos Tapes, por extensão), na atualidade, encontramse "operacionalizados através de políticas públicas e de ações que objetivam tornar positiva a identidade local" (FERREIRA; HEIDEN, 2009, p. 150). Os pesquisadores consideram que, se por um lado essa proeminência salvaguarda muitos bens culturais de sua destruição ou desaparição completa, por outro lado, a forma como muitas dessas ações vem ocorrendo, mobilizando imaginários, construindo verdades absolutas, precisa ser questionada. Weber e P. Bosenbecker (2010), por seu turno, avaliam que essa "supervalorização" da cultura pomerana na região deve-se, principalmente, às disputas atuais provocadas por uma reavaliação sócio-cultural da conjuntura local, a qual visa à afirmação da cultura pomerana e que envolve tanto novas políticas no nível municipal e regional, quanto oportunidades de desenvolvimento econômico motivadas pelo turismo. O principal catalizador desta "positivação" da identidade pomerana foi o revival pomerano promovido pelo poder público de São Lourenço do Sul a partir das comemorações do Sesquicentenário da Imigração Alemã-Pomerana, realizadas no ano de 2008.

No contexto musical da comunidade de descendentes de pomeranos da colônia São Lourenço, destaca-se o Musical Boa Esperança, primeiro conjunto musical a compor e gravar músicas em pomerano na região. Na estrada desde 1991 (HAMMES, 2014, p. 446), o conjunto foi fundado pelos irmãos Almiro Hörnke (o Miro), cantor, guitarrista e compositor, Egon Hörnke, contrabaixista, e Wolnei Hörnke (o Neiki, baterista), tendo sua formação variado desde então. À época de minha etnografia musical pomerana, durante o ano de 2016, juntamente aos irmãos Hörnke tocavam Félix Tessmann (teclado, acordeon, trompete e saxofone), Rudinei Hartwig (trompete), Ênio Hartwig (trombone e acordeon), além da participação dos meninos Rodrigo Hörnke (trompete, guitarra), Otto Tessmann (trompete) e Rafael Hörnke (contrabaixo), os quais revezam com os instrumentistas oficiais para descanso desses e para seu próprio desenvolvimento musical. O Musical Boa Esperança toca geralmente aos finais de semana em festas tradicionais pomeranas, 
como casamentos, confirmações ${ }^{7}$, bodas, festas de comunidades religiosas e bailes de sócios e de casais.

Através de pesquisa etnomusicólogica junto à bandinha ${ }^{8}$, pude encontrar uma versão em pomerano de Jambalaya (on the Bayou) - agora, "na colônia". Álas folóra9 foi gravada pela bandinha em maio de 2017 com arranjo para metais (influência da música tradicional pomerana) e em ritmo de vaneira (influência da música tradicionalista gaúcha), um notável exemplo de hibridismo cultural, sem mencionar seu pré-hibridismo - a relação de Jambalaya com Le garçon negligent, uma canção cajun.

\section{Hibridismos e memória cultural}

A multiplicidade de elementos técnico-musicais, poéticos, processos sociais, históricos, culturais, dentre outros ligados à cultura que envolve a(s) música(s) popular(es), desafia qual(is)quer empreitada(s) no intuito de compreendê-la(s). Um desses desafios se dirige ao fato de que a música popular também se caracteriza como um "híbrido de tradições, de estilos e influências musicais" (SHUKER, 2005, p. XII).

Néstor García Canclini (2011) corrobora essa perspectiva de ressignificações quando menciona exemplos de cruzamentos (hibridações) musicais através de termos como fusão, mistura, reinterpretação e reelaboração no universo da música popular.

Algo frequente como a fusão de melodias étnicas com a música clássica e contemporânea ou com o jazz e a salsa pode ocorrer em fenômenos tão diversos quanto a chicha, mistura de ritmos andinos e caribenhos; a reinterpretação jazzística de Mozart, realizada pelo grupo afro-cubano Irakere ${ }^{10}$; as reelaborações de melodias inglesas e hindus efetuadas pelos Beatles, Peter Gabriel e outros músicos (CANCLINI, 2011, p. 20).

O referido autor apresenta uma ampla reflexão acerca da complexidade envolvida na noção de hibridação, principalmente pelo fato de que tal noção passou a modificar, a partir de fins do século XX, os modos de se falar sobre "identidade, cultura, diferença, desigualdade, multiculturalismo", além de inserir-se em discussões sobre trânsitos como “tradição-modernidade, norte-sul, local-global”. Nesse escopo, são variados os enfoques, temáticas e peculiaridades teórico-metodológicas: 
Ele [hibridismo] é usado para descrever processos interétnicos e de descolonização (Bhabba, Young); globalizadores (Hannerz); viagens e cruzamentos de fronteiras (Clifford); fusões artísticas, literárias e comunicacionais (De la Campa; Hall; Martín Barbero; Papastergiadis; Webner). Não faltam estudos sobre como se hibridam gastronomias de diferentes origens na comida de um país (Archetti), nem da associação de instituições públicas e corporações privadas, da museografia ocidental e das tradições periféricas nas exposições universais (Harvey) (CANCLINI, 2011, p. XVIII).

Nesse sentido, o hibridismo se define como "[...] processos socioculturais nos quais estruturas ou práticas discretas, que existiam de forma separada, se combinam para gerar novas estruturas, objetos e práticas". Essas “estruturas discretas” já são frutos de hibridações anteriores, o que leva a questionar a própria noção de pureza das fontes. Tratam-se de "ciclos de hibridação": "passamos de formas mais heterogêneas a outras mais homogêneas, e depois a outras relativamente mais heterogêneas, sem que nenhuma seja 'pura' ou plenamente homogênea” (CANCLINI, 2011, p. XIX-XX). Ou seja, trata-se de um continuum hibridizante.

O olhar sobre processos híbridos questiona noções essencialistas (representações de pureza, autenticidade) acerca das identidades culturais. Através da "abstração de traços (língua, tradições, condutas estereotipadas)", noções essencialistas "definem" as identidades a partir de modos absolutizados de representar as realidades, rejeitando "maneiras heterodoxas de falar a língua, fazer música ou interpretar as tradições" (CANClINI, 2011, p. XXII-XXIII). Em Hibridismo Cultural (2003), Peter Burke também apresenta o contexto intelectual atual como meio questionador de pontos de vista essencialistas em relação à cultura:

Um dos sinais do clima intelectual de nossa época é o uso crescente do termo "essencialismo" como modo de criticar o oponente em todo tipo de discussão. Nações, classes sociais, tribos e castas têm todos sido "desconstruídos" no sentido de serem descritos como entidades falsas (BURKE, 2003, p. 14).

As sociedades contemporâneas, segundo Hall (2011), são marcadas por processos de fragmentação cultural, de classe, de gênero, sexualidade, etnias, cujo efeito é a “perda de um sentido de si”. Novos contextos em que as identidades, antes percebidas como estáveis, passaram a ser analisadas no interior de um processo de deslocamento 
e fragmentação, e os indivíduos, antes concebidos como portadores de uma identidade fixa, passaram a ser concebidos como indivíduos descentrados, podendo assumir diferentes posições identitárias, em diferentes momentos. Ainda de acordo com Hall (2002), a identidade cultural apresenta-se sob dois focos: o primeiro refere-se à cultura compartilhada em sociedade ou nação, aquela que reflete experiências históricas comuns consolidadas em códigos e referências; o segundo foco refere-se, complementarmente ao primeiro, à experiência individual que agrega valores e referências a uma cultura, tornando-se mecanismo de transformação, mudança e adaptação dessa.

Uma identidade artístico-cultural híbrida pode ser induzida ou acentuada pelos processos globalizadores que facilitam intercâmbios interculturais conformados através de "mercados mundiais de bens materiais e dinheiro, mensagens e migrantes". Estes intercâmbios favorecem fluxos e interações que diminuem distâncias entre fronteiras físicas e simbólicas, bem como o enfraquecimento de autonomias autocentradas de contextos locais:

Às modalidades clássicas de fusão, derivadas de migrações, intercâmbios comerciais e das políticas de integração educacional impulsionadas por Estados nacionais, acrescentam-se as misturas geradas pelas indústrias culturais. (CANCLINI, 2011, p. XXXI)

Tais processos interculturais geram fenômenos transculturais ${ }^{11}$. Tais fenômenos embolam a possibilidade de sequências históricas lineares, gerando uma trama, composta por espirais - recuperando a metáfora de Morin (1969) -, que se entrelaçam formando novas espirais.

Segundo Ulhôa et al (2001, p. 352), a música popular é multifacetada em suas diversas manifestações (regionais, étnicas, locais, nacionais), circula através dos meios de comunicação (o que a faz participar dos processos ligados à globalização), e "tem se apropriado, reproduzido e recombinado blocos de significação de várias matrizes, sejam elas cultas, artesanais ou industriais". A distribuição mundial de bens de consumo, como os CDs, por exemplo, bem como canções veiculadas através do rádio, da televisão e da internet, refletem uma perspectiva pouco atentada: a disseminação global de conteúdos estético-musicais que ficam disponíveis ao acesso e à apropriação de músicos das mais 
variadas localidades do planeta. Isso apresenta uma perspectiva de acesso a informações potencialmente hibridizáveis que podem ser postas em prática por músicos de outro lugar do mundo com a simples atividade de tirar de ouvido, tocar em seu instrumento e refletir (através de sua visão de mundo formada por suas experiências musicais e de vida) sobre esse material sonoro disponibilizado e acessado via audição e execução ao instrumento.

Jan Assmann (ASSMANN; CZAPLICKA, 1995) procura desenvolver um campo teórico-conceitual que dê suporte às discussões culturais acerca da memória e da identidade, em que se insere esse estudo. Conforme o autor, o sentido de pertencimento a uma determinada sociedade, grupo, etnia, ou cultura é visto como o resultado da socialização de costumes que se dá na interação entre as pessoas. Dessa forma, a sobrevivência dos tipos sociais está permeada e apoiada pelos aspectos que envolvem o conceito de memória cultural. Esse conceito procura dar conta de "todo conhecimento que dirige o comportamento e experiência na estrutura interativa de uma sociedade e que é obtido através de gerações em repetidas práticas e iniciações societais" (ASSMANN; CZAPLICKA, 1995, p. 126). Nota-se, portanto, que a noção de memória cultural trazida pelo autor visa a abarcar uma perspectiva mais culturalizada (e comunicativa) da noção de memória coletiva e de identidade, onde se consideram processos de transmissão, interação e aprendizagem, bem como os mecanismos pelos quais tais operações funcionam dentro de uma comunidade. Para Assmann, o processo comunicativo é elemento chave para a constituição da memória cultural e, para tal, caracteriza o que nomeia como memória comunicativa. Esse tipo de memória se constrói através daquelas "memórias coletivas que estão baseadas exclusivamente sobre comunicações do dia-a-dia" (ASSMANN; CZAPLICKA, 1995, p. 126), as quais se caracterizam pela não especialização, pela reciprocidade de papéis, pela instabilidade temática e desorganização. E é a partir desse tipo de comunicação, ou seja, na interação com os outros, que cada indivíduo vai compondo sua própria memória, estabelecendo, consequentemente, sua própria identidade cultural.

Assmann, a seguir, trata da questão da transição no escopo da memória comunicativa. Elemento fundamental para se compreender os processos através dos 
quais as pessoas de uma comunidade se comunicam, esse processo comunicativo se dá, conforme sua teoria, através de uma memória cristalizada em produções (o que denomina “textos culturais"). Dessa forma, seria através desses produtos que os conhecimentos que estruturam um determinado grupo são objetivados 12 (“objetificados"), se materializariam. Assmann vê no contexto da cultura objetivada ("objetificada"), cristalizada em canções, contos, ritos, construções, monumentos, etc., uma estreita conexão entre os membros do grupo e sua identidade. Conforme o autor:

Podemos nos referir à estrutura do conhecimento neste caso como a concreção da identidade. Com isso, queremos dizer que um grupo baseia sua consciência de unidade e especificidade sobre este conhecimento e deriva impulsos formativos e normativos a partir deste, o qual permite ao grupo reproduzir sua identidade. (ASSMANN; CZAPLICKA, 1995, p. 128)

É através desse tornar-se concreto que a memória cultural preserva o armazenamento dos conhecimentos através dos quais o grupo deriva o reconhecimento de sua unidade e peculiaridade. Esse "reconhecimento de si", para Assmann, parte de definições identificatórias de significados. Nesse sentido, a música porta aspectos memorias e identitários da comunidade que a cria.

A capacidade para reconstruir uma memória cultural opera na medida em que os membros do grupo, bem como as interações que daí vem à tona, relacionam o seu conhecimento a situações contemporâneas. Embora existam qualidades imóveis de memória e armazenamento de conhecimentos, os contextos contemporâneos se relacionam aos produtos dessa memória através de apropriações, preservações, transformações. Exemplo disso são as músicas populares autorais pomeranas de origem tradicional existentes na região da Serra dos Tapes, as quais são compostas tendo como embrião algum trecho musical conhecido tradicionalmente.

A formação da memória cultural é uma característica que dá conta da cristalização do significado comunicado e do conhecimento coletivamente compartilhado como pré-requisitos para a transmissão de uma herança cultural institucionalizada de uma sociedade. Para tal, não somente a escrita atua como forma para uma formação cultural estável: imagens pictóricas, rituais, bem como outras formas - como, no tocante à 
referida pesquisa, a música - funcionam para a cristalização e compartilhamento de uma herança cultural.

O autor, ao final de seu artigo, sintetiza o conceito de memória cultural:

O conceito de memória cultural compreende aquele corpo de textos, imagens e rituais reutilizáveis específicos a cada sociedade e em cada época em que a cultivação serve para estabilizar e transmitir a autoimagem dessa mesma sociedade. Sobre tal conhecimento coletivo, a maior parte (mas não exclusivamente) do passado, cada grupo baseia sua consciência de unidade de particularidade.

(ASSMANN; CZAPLICKA, 1995, p. 132)

Assim, apoiando-se no conceito de memória cultural de Assmann e de hibridismo de Canclini, esse artigo dedicou-se a analisar o percurso cultural percorrido pela melodia originária de Jambalaya (on the Bayou) (1952), a canção cajun Le garçon negligent (1928), até culminar na versão pomerana do Musical Boa Esperança, Álas folóra (2017), cobrindo quase um século de versões, transmissões culturais e hibridismos.

\section{Um jambalaia na colônia}

Jambalaya (on the Bayou) ${ }^{13}$ é uma canção gravada em 1952 pelo cantor country estadunidense Hank Williams (1923-1953) que gerou muitas versões e alcançou popularidade em vários gêneros musicais (ESCOTT, 2004). Seu título faz menção a um prato da cozinha cajun, uma espécie de paella de influência multicultural, bastante apreciada no estado da Luisiana, Estados Unidos (SIGAL, 2007, p. 102).

Lançada em 1952, creditando Williams como o único autor da letra e da melodia, Jambalaya (on the Bayou) foi apresentada pelo cantor como uma música country. Atingiu o número um nas paradas dos EUA por quatorze semanas e continua sendo, até hoje, uma das músicas mais populares do referido cantor.

De acordo com Wade Falcon ${ }^{14}$, violinista e pesquisador cajun, pelo fato de a melodia original ser de uma música francesa cajun chamada Le garçon negligent ${ }^{15}$, a música é um constante da cultura cajun. Quanto à letra, enquanto Le garçon negligent enfoca um drama em que a amada do eu-lírico vai embora com outro por causa de um "garoto negligente", o próprio eu-lírico que teria negligenciado seu amor, Jambalaya (on the Bayou), por seu turno, versa sobre a vida, festas e comida estereotipada da culinária 
cajun - possivelmente inspirada pelo tempo que Williams passou na Louisiana. Nesta canção, são mencionados pratos cajun como jambalaia, torta de lagosta e filé gumbo, mas Williams também se refere a uma personagem feminina em sua letra, Yvonne, referindose a ela como minha "ma cher amio", que significa em cajun francês "minha querida".

Contudo, ainda de acordo com o pesquisador ${ }^{16}$, existe um percurso cultural percorrido pela melodia de Le garçon negligent que, antes de culminar em Jambalaya (on the Bayou), relaciona com Big Texas. Segundo sua pesquisa, a originária Le garçon negligent data de 1929, mas entre 1934 e 1940, esta melodia teria influenciado músicas como La valse de Bayou Plaquemine, dos Breaux Brothers, Pin solitaire, de Cléoma Breaux, Lake Arthur waltz e Pine Island, de J. B. Fusilier, Gran Prairie, de Happy Fats, Abbeville, dos Jolly Boys, e uma música chamada Allons Kooche Kooche, dos Louisiana Rounders. Quando Jules Angelle "Papa Cairo" Lamperez voltou à cena musical após a Segunda Guerra Mundial, ele não conseguiu esquecer a melodia que usou na canção dos Louisiana Rounders, grupo do qual era integrante. Cairo estava determinado a torná-la uma música popular fora da Luisiana e do Texas.

Pouco antes de 1947, Murphy "Chuck” Guillory decidiu adicionar Julius "Papa Cairo" Lamperez à sua formação musical. Em 1948, Cairo pediu para a banda de Chuck tocar a melodia acima referida e deu-lhe o título de Big Texas, prensada em um shellac red label e mais tarde em um vinil mais leve, etiqueta azul.

De acordo com o pesquisador, não se sabe ao certo qual gravação antes da guerra influenciou a melodia de Papa para a canção, mas ele escreveu sua própria versão da letra. Big Texas era uma música sobre um amante rejeitado que começava uma nova vida na terra distante de aventura e grande desconhecida... o grande Texas. Como a canção era cantada em francês, ele sabia que seu sucesso seria limitado. Em 1949, Cairo decidiu gravar a canção em inglês com seu próprio grupo e intitulou-a Big Texas 2, seguindo-a com sua versão original em francês de antes da guerra, chamada simplesmente de Kooche Kooche.

Em 1952, o astro do país Hank Williams já era capaz de se orgulhar de seis grandes sucessos nas paradas e sete milhões de discos vendidos, antes de chegar à gravação de Jambalaya (on the Bayou). De acordo com Escott (Instantâneos da estrada perdida), Big 
Bill Lister disse que Moon Mullican (embora este não conste nos créditos da canção) e Hank Williams compuseram Jambalaya juntos enquanto viajavam na limusine de Hank a caminho de um show na Luisiana e que Don Helms (braço direito de Hank) escreveu as palavras. Contudo, para Falcon ${ }^{17}$, Le garçon negligent, uma curta gravação feita pelos Guidry Brothers - grupo do sul da Luisiana - para a Vocalion em 1929 foi a precursora de Jambalaya, percorrendo, para tanto, um intrincado percurso cultural (Diagrama 1).

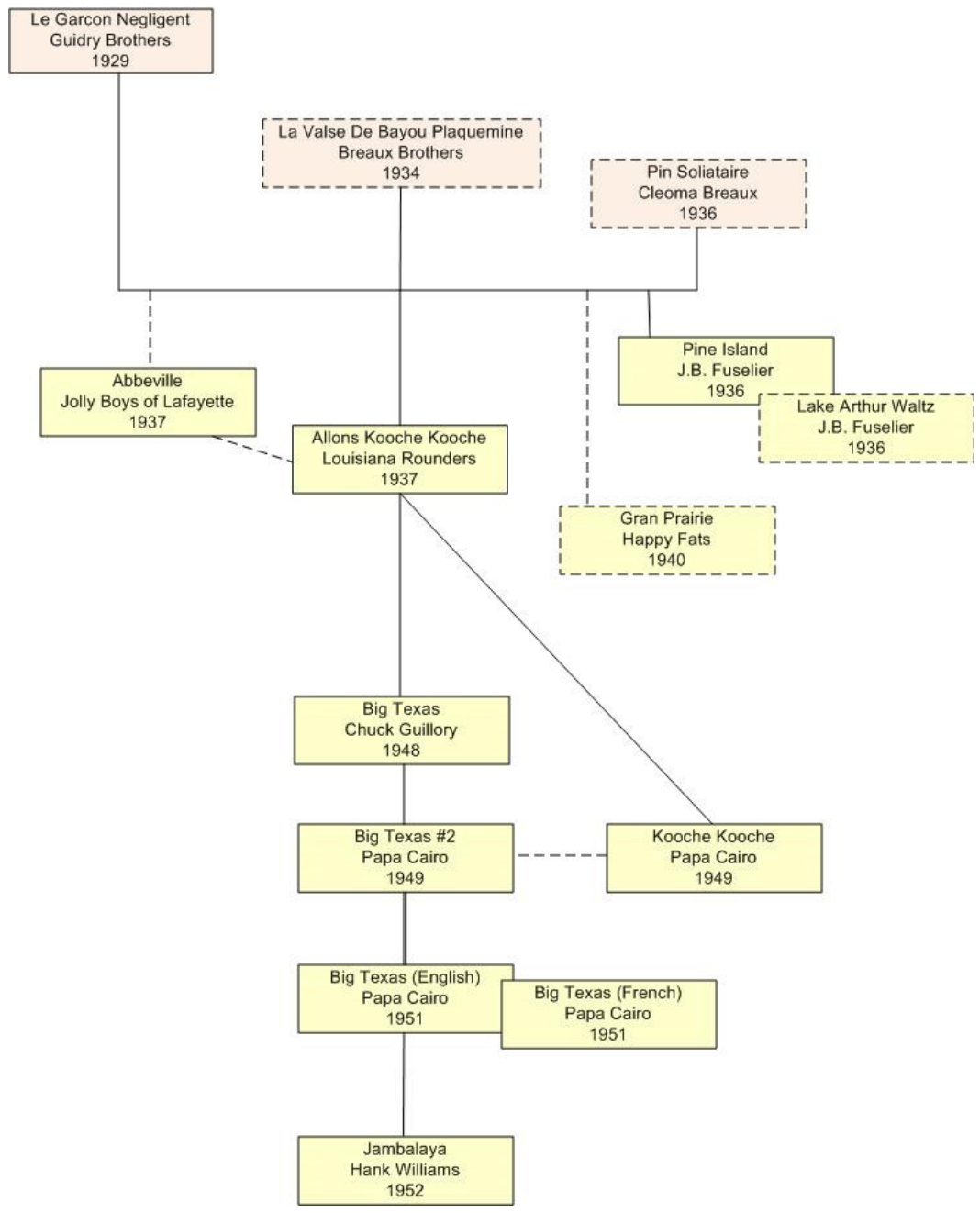

Diagrama 1: Percurso cultural percorrido por Le garçon negligent nos Estados Unidos até Jambalaya (on the Bayou) ${ }^{18}$. 
A apropriação country de uma melodia cajun, caracterizado através de um híbrido de tradições, estilos e influências musicais, é um exemplo de processo cultural onde estruturas que existiam de forma separada se combinam para gerar novas estruturas. Enquanto Le garçon negligent é cantada em francês cajun, se baseia em um compasso binário e se utiliza dos instrumentos violão, acordeon e fiddle (estes aparecendo somente nos solos de interlúdio entre as estrofes), Jambalaya (on the Bayou) é cantada em inglês, possui um compasso quaternário alinhado e se utiliza de instrumentação mais expandida, como violão de aço, percussão e guitarra - embora o tradicional fiddle cajun também sole nos interlúdios. Vale lembrar que, mesmo em se tratando das primeiras décadas do século $\mathrm{XX}$, tanto o rádio quanto a indústria de discos norte-americana tiveram papel importante na difusão e na consequente hibridação entre a música cajun e a música country, facilitando a circulação e possibilitando o acesso ao repertório e ao material sonoro em si.

Por seu turno, a utilização de uma melodia cajun por parte de Hank Williams para dar voz justamente a uma letra referente à culinária e a cultura cajun soa intencional, haja vista que uma melodia familiar beneficia, em tese, a aceitação de versos relativos uma cultura específica. Neste caso, uma memória cultural, cristalizada na melodia de Le garçon negligent, tende a contribuir para a aceitação de Jambalaya (on the Bayou) dentro da comunidade cajun, potencializando o seu sucesso a partir do reconhecimento identitário. A transmissão cultural reside na melodia reconhecível, através de apropriação, preservação e transformação de elementos constituintes. Se o conceito de "memória cultural" inclui a música de uma sociedade em uma determinada época, e sua cultivação serve para estabilizar e transmitir a autoimagem dessa mesma sociedade, Jambalaya consegue, mais por conta de sua melodia originária que por sua letra estereotipada, transmitir a autoimagem da sociedade cajun local.

Pouco antes de começar meu trabalho de campo, em 2016, tocando bandoneon junto ao Musical Boa Esperança para etnografar festas tradicionais pomeranas, como casamentos, confirmações, bodas, festas de comunidades religiosas e bailes de sócios e de casais, fui informado, por meio de um telefonema do líder da bandinha - o músico/ 
compositor Almiro Hörnke, conhecido como Miro -, que «seria bom» se eu tocasse músicas instrumentais ao meu instrumento, acompanhado pelo conjunto.

Nesse processo preparatório, procurei ensaiar canções que se mostrassem apropriadas para o contexto musical alemão/pomerano da região, de meu conhecimento prévio devido à pré-etnografia ${ }^{19}$ realizada através das apresentações anteriores com a bandinha: chotes, valsas, polcas e vaneiras eram os gêneros musicais mais utilizados pelo Boa Esperança. As primeiras canções estudadas por mim eram de autoria da própria bandinha ou já executadas por ela, mas agora seriam tocadas em versão instrumental. No entanto, ainda faltava uma vaneira no repertório pessoal do aprendiz de bandoneonista...

Ao refletir sobre isso, lembrei-me que, na primeira vez em que toquei com a bandinha, ouvira uma canção instrumental em ritmo de vaneira/forró e que se fazia ouvir nas caixas de som durante um momento de descanso do grupo, enquanto um dos integrantes deixava rodar, a partir de um notebook, músicas para servirem de fundo musical. A referida canção era uma versão instrumental de Fica amor ${ }^{20}$, composta e gravada pelo cantor capixaba Alemão do Forró, que obteve determinado sucesso dentro do mundo da música de baile no Brasil. A melodia e a harmonia foram de fácil assimilação e, com algum treinamento de simultaneidade de mãos, de acompanhamento e melodia, em pouco tempo Fica amor estava pronta para ser tocada junto à bandinha. Quando a mostrei aos músicos do conjunto a canção, eles de pronto exclamaram: “Tu sabe tocar João Balaio"! A bandinha conhecia Fica Amor como João Balaio. E gostavam muito da canção.

Em outro contexto musical, a partir dos preparativos para uma apresentação com meu pai, Adão Quevedo, na Inauguração da Praça Central de São Lourenço do Sul, no dia 16 de junho de 2016, o referido músico, ao ensaiar a música denominada pela bandinha João Balaio, disse reconhecê-la como uma canção country, intitulada Jambalaya. Logo, através de pesquisa na internet, identifiquei a canção João Balaio $^{21}$, do quarteto vocal brasileiro Boca Livre - da qual aparentemente Fica amor era uma versão -, cujo título era acompanhado por uma palavra em inglês: João Balaio (Jambalaya). Localizei, então, a canção Jambalaya (on the Bayou) ${ }^{22}$, uma canção country estadunidense do cantor Hank Williams, gravada em 1952 (ESCOTT, 2004, p. 213), da qual as demais versões eram 
oriundas. Para completar o círculo, ainda na mesma pesquisa, encontrei uma versão para Jambalaya do cantor gaúcho Mano Lima, também intitulada João Balaio ${ }^{23}$, a qual era, efetivamente, uma vaneira.

Em geral, João Balaio instrumental era tocada nos toques ${ }^{24}$ da bandinha solada ao bandoneon, mão direita, com acompanhamento de acordes na mão esquerda em ritmo de vaneira, acompanhada por bateria, contrabaixo e guitarra base, e com contracantos rítmico/melódicos executados ao teclado, com timbre de acordeon, em momentos em que os metais descansavam. O apreço do Boa Esperança ao João Balaio era tanto que, em maio de 2017, Miro escreveu sua própria versão, em pomerano, de Jambalaya, Álas folóra, a qual foi arranjada e gravada (em estúdio caseiro) pela bandinha e distribuída a rádios da região, além de ter sido produzido um videoclipe veiculado na internet através do YouTube ${ }^{25}$ (canal Pomeranos TV, publicado em 02 de junho de 2017), tendo atingido considerável sucesso, angariando, inclusive, vários contratos para o conjunto ${ }^{26}$.

Álas folóra foi gravada no estúdio caseiro da bandinha, localizado em um galpão na propriedade de Miro, localidade de Santa Augusta, interior de São Lourenço do Sul ${ }^{27}$. A canção conta com arranjo para metais - dois trompetes - na introdução, que é repetida ao final de cada refrão. O acompanhamento é realizado pela bateria, pelo contrabaixo, pela guitarra e pelo teclado. É com essa instrumentação que Miro canta, em pomerano, seu jambalaia na colônia, com certa liberdade rítmico/melódica, sem demasiado compromisso com a versão original ou com quaisquer outras versões - ainda assim, o contorno melódico de Jambalaya (on the Bayou) é facilmente reconhecível.

Quanto à letra, Álas folóra não guarda quaisquer semelhanças com Jambalaya, ou com João Balaio do Boca Livre ou do Mano Lima, ou, ainda, com o Fica amor do Alemão do Forró. A letra, em pomerano, trata da crise política e econômica que vivia o Brasil à época, contextualizada no habitat alemão/pomerano, colonial, de ethos camponês. Relatos sobre a crise são escutados no rádio, e seus reflexos são verificados em problemas rurais cotidianos. Por fim, por conta da tal crise, está "tudo perdido", diz a canção. A seguir, disponibiliza-se (Fig. 1) a letra da canção Álas folóra ("Tudo perdido") 28 - versão do Musical Boa Esperança de Jambalaya (on the Bayou), de Hank Williams em pomerano e com sua tradução para o português. 


\section{ÁLAS FOLÓRA}

Ik hef hêit in min rádio mit pilhas áin schlim tit kimp in úza Brazilian. Hef al kéf áina bái un áin rozilha, gasolina is fel díra as dái milha. Nu dáuk fúira mit áina scharét, óva dái hef al fokéf vêia schevét. Ven zôu blift gasolína krícha ni kéft, den is béta pêia ut bína mânga millha.

Vi búcha hưina schtal un schuín búchta, dái melk dáuf foschika dem melk fúira. Ven nich plânda den fêihalt tam étan, den zéchas dái konista héva schult. Ven vi úpa koní us tôup stóch, rakf mit vurst den rikt uk nam púlva. Vi búscha mit hex un mit zíchal, ven mut zin dái Brazilian búscha vi gró.

Grôuda kêils é lon is véra stéia, mía lon dáu ik nía mêia krícha.

Licht is stéia, "oh que barbaridade», ven zôu blift kan mi bóra áis up vek. Strot is schelt vif góina fon fotéla, "cobríra» álas un lócha kríchas ni táuch. Zôu ast is us Brazilian hêit nich fórbeist, ven zôu blift is doch álas folóra.

\section{TUDO PERDIDO}

Hoje eu escutei no meu rádio de pilha, um tempo difícil vem no nosso Brasil. Já comprei um baio e uma rosilha, gasolina é mais caro que o milho. Agora ando com uma charrete, mas já vendi por causa do Chevette. Se ficar assim gasolina não consigo comprar, aié melhor atar os cavalos no milho.

Nós construímos galinheiros e chiqueiros, O leite vendemos para o leiteiro.

Se não plantamos então falta comida, aí dizem que os colonos são os culpados. Se na colônia nos unirmos, mexemos com linguiça daí cheira à pólvora. Nós roçamos com machado e foice, se for preciso o Brasil nos endireitamos.

Dos governantes o salário subiu de novo, o meu salário eu não ganho mais. A luz subiu de novo oh que barbaridade, se ficar assim tomo banho uma vez por semana A estrada está ruim nem vamos falar, cobram tudo e os buracos não conseguem tapas Desse jeito nosso Brasil não vai pra frente, se ficar assim está tudo perdido.

Figura 1: Letra da canção Álas folóra, do Musical Boa Esperança, em pomerano e tradução para português (tradução e escrita do pesquisador e da colaboradora Olívia Tessmann).

No entanto, apesar de não guardar semelhanças com a canção original e com as versões citadas anteriormente, a partir de nova pesquisa na internet consegui localizar uma versão intitulada Jambalaia do alemão, do cantor e humorista Maurício Pflugseder, o Alemão de Lageode ${ }^{29}$. Este cantor declara-se de origem hunsriqueana ${ }^{30}$, morador do município de Lageado, estado do Rio Grande do Sul, Brasil, pronunciado Lageode pela comunidade hunsriqueana local ${ }^{31}$. Álas folóra, apesar de ser cantada em pomerano, guarda muita parecença com Jambalaia do alemão que, muito embora faça menção à versão original no título, discorre sobre a crise política e econômica do Brasil e cita muitos eventos citados na versão do Boa Esperança - a versão de Pflugseder é tratada por ele mesmo como uma paródia de Jambalaya ${ }^{32}$. Além disso, a versão do Alemão de Lageode é cantada um pouco em português e um pouco em hunsriqueano - evidenciando um 
bilinguismo evidente e facilitando a compreensão por parte do público não hunsriqueano - e sua instrumentação, esta sim, remete à canção original, i.e., ao contrário da versão do Musical Boa Esperança, Jambalaia do alemão não contém elementos musicais oriundos da tradição alemã/hunsriqueana/pomerana, e sim, características da música country expressas principalmente no arranjo de guitarras e na rítmica da bateria. A relação entre as letras e também a data de lançamento das canções ${ }^{33}$ denotam que o Musical Boa Esperança se baseou na versão do Alemão de Lageode para compor sua própria versão, apropriando-se de ideias de Jambalaia do alemão e traduzindo-as para pomerano, mas também inseriu novas ideias e, principalmente, como evidencia a última estrofe, compôs um final diferente, o qual deu origem ao título da canção.

Todo esse percurso cultural (Diagrama 2) foi percorrido por Jambalaya (on the Bayou) no Brasil até chegar à Álas folóra, i.e., a canção country estadunidense promoveu várias versões que incidiram no seu conhecimento e apropriação por parte da bandinha pomerana: João Balaio (Boca Livre, 1989), pertencente ao contexto da música popular brasileira, MPB, responsável pela adaptação do título original para o nome/apelido em português pelo qual a bandinha conhecia a melodia; João Balaio (Mano Lima, 1995), atrelada à música tradicionalista gaúcha e precursora do avaneiramento de Jambalaya; Fica amor (Alemão do Forró, 2013), oriunda do mundo da música de baile e promotora do sucesso recente (re)atingido pela melodia no Brasil e da inserção de elementos musicais do gênero forró, advindo da música regional nordestina; Jambalaia do alemão (Alemão de Lageode, 2015) 34 $^{34}$ versão “étnica” de Jambalaya (hunsriqueana), responsável pela inspiração letrística por parte do Musical Boa Esperança para a escrita de sua versão em pomerano; e João Balaio instrumental (Autor, 2016) ${ }^{35}$, incitadora da utilização da melodia para uma versão em pomerano. Esse ciclo culminou em Álas folóra (Musical Boa Esperança, 2017) ${ }^{36}$, com melodia de Jambalaya (adaptada) e com letra contendo trechos (adaptados para pomerano) de Jambalaia do alemão (Maurício Pflugseder, em português e hunsriqueano) e trechos autorais. Além da pomeranização da letra, o Musical Boa Esperança também pomeranizou a instrumentação, valendo-se de tradições musicais endógenas, de dentro de sua cultura, atreladas à sua tradição. No entanto, a adoção do gênero musical vaneira/forró denota a influência de tradições musicais exógenas à 
pomerana, no que se refere à música tradicionalista gaúcha e à música regional nordestina. Outrossim, a canção original, Jambalaya (on the Bayou), além de provir de outra tradição musical exógena (a música country norte-americana), também tem um histórico híbrido, valendo-se de tradições musicais cajuns.

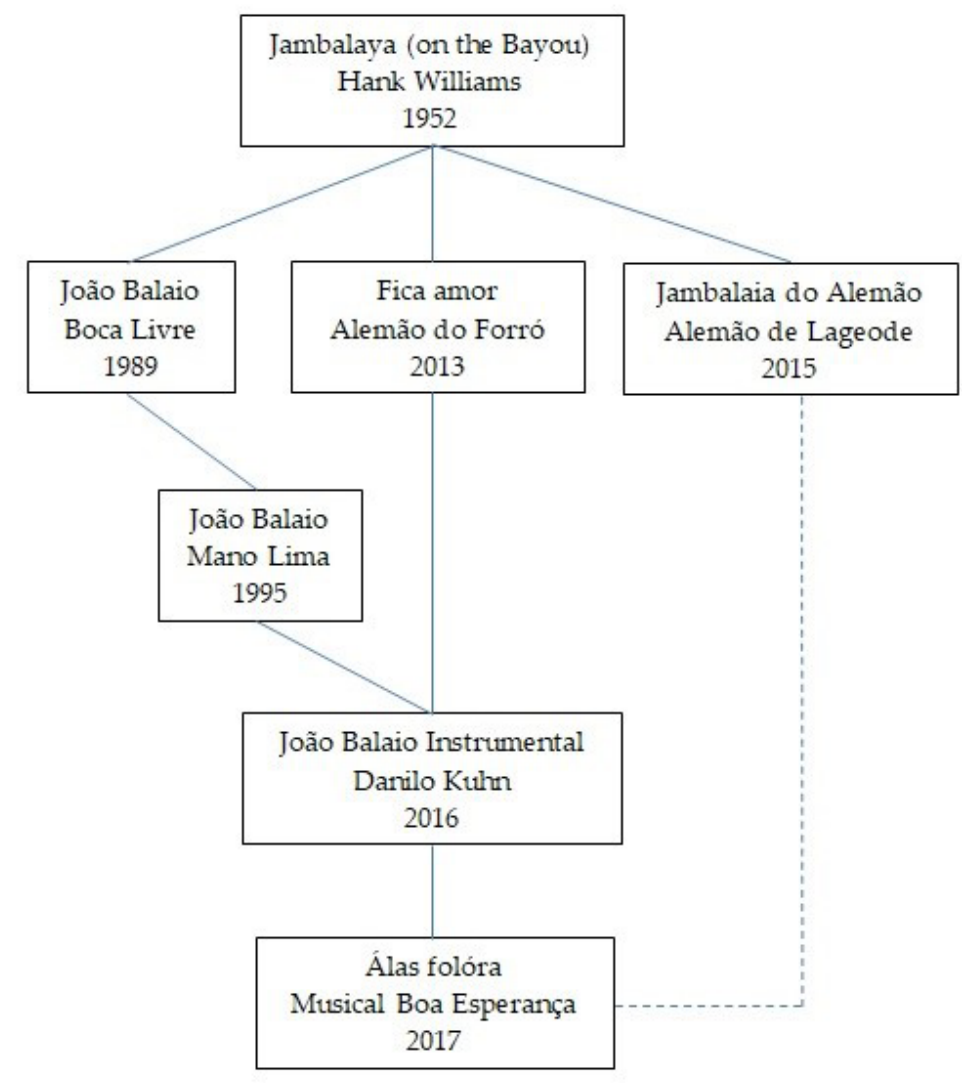

Diagrama 2: Percurso cultural de Jambalaya (on the Bayou) no Brasil até Álas folóra (diagrama do autor).

Em seu particular híbrido de tradições, estilos e influências musicais, o Musical Boa Esperança, mesmo sem conhecer Jambalaya (on the Bayou) ou Le garçon negligent, apropriou-se de uma canção originariamente cajun e posteriormente country e a pomeranizou. Contudo, o percurso cultural percorrido no Brasil influiu em sua apropriação, seja pelo conhecimento do nome abrasileirado, seja pelo avaneiramento já experimentado 
na versão gaúcha, seja pelo sucesso atingido pela versão forró, seja pela aceitação, por parte de seu público, da versão instrumental ao bandoneon, seja pela adaptação da letra da versão hunsriqueana. Ainda assim, mesmo com todo este hibridismo evidente - algo que poderia distanciar a canção de seu público-alvo -, Álas folóra atingiu notável sucesso radiofônico local, bem como nos eventos onde a banda toca, garantindo-lhe muitos contratos e indicando que a pomeranização utilizada encontrou eco na comunidade, isto é, a canção foi reconhecida como representativa da cultura local. Podem-se citar, entre as estruturas concomitantes combinadas pelo Boa Esperança, a canção cajun/ country estadunidense, o gênero musical gaúcho vaneira, o gênero musical nordestino forró, além de sua própria tradição musical pomerana. E, neste caso específico, processos globalizadores como veículos de comunicação de massa (rádio, televisão) e a internet foram preponderantes no que tange o acesso, por parte da bandinha, às versões anteriores à sua Álas folóra. Inclusive, a própria divulgação da canção, exclusivamente via rádios locais e clipe na internet, denota a sintonia do Musical Boa Esperança com a globalização e a tecnologia que lhe é inerente.

Neste sentido, os processos contemporâneos de fragmentação cultural destacados por Hall (2011) evidenciam que as identidades, inclusive a identidade pomerana, antes percebidas como estáveis, precisam ser analisadas dentro de um quadro de deslocamento e fragmentação, onde os indivíduos, também antes concebidos como portadores de uma identidade fixa, passaram a ser concebidos como indivíduos descentrados, podendo assumir diferentes posições identitárias, em diferentes momentos. A comunidade pomerana da Serra dos Tapes, por ser também gaúcha e brasileira e mundial, é, em si mesma, híbrida. Se, ainda de acordo com Hall (2002), a experiência individual agrega valores e referências a uma cultura, tornando-se mecanismo de transformação, mudança e adaptação dessa, tanto o Musical Boa Esperança, ao incorporar elementos de música cajun/country, de música gaúcha e de música nordestina à sua música pomerana, quanto seu público, aceitando tais referências, corroboram Hall e Canclini, quanto à sua visão de uma cultura fragmentada e hibridizada.

Quanto à memória cultural, tanto a instrumentação de Álas folóra, baseada em instrumentos de sopro, quanto a letra de ethos camponês e em pomerano, foram capazes 
de associar a canção à identidade da comunidade, embora o hibridismo notório. Ao apropriar-se de elementos externos, advindos da música cajun/country norte-americana, da música gaúcha e da música nordestina, mas, ao mesmo tempo, preservar elementos de sua cultura, o Musical Boa Esperança criou uma canção fortemente híbrida, porém, ainda capaz de transmitir sua herança cultural pomerana a seu público, produzindo o novo como híbrido musical recriado de tradições exógenas dentro de tradições endógenas.

\section{Aspectos conclusivos}

A partir de pesquisa etnomusicológica realizada, identificou-se a canção Álas folóra, do conjunto Musical Boa Esperança, como um exemplo de incorporação de práticas exógenas, através de hibridismos, consonante às práticas endógenas na música alemã/pomerana da região da Serra dos Tapes, sul do estado do Rio Grande do Sul, Brasil. Através de pesquisa na internet, conclui-se que a canção originária da versão pomerana é a longínqua Le garçon negligent, uma canção cajun gravada pela primeira vez na Luisiana, Estados Unidos, em 1928, pelos Guidry Brothers, mas que trabalha uma memória cultural que remete ao Canadá, mais especificamente à Acádia, que dá a referência a esta comunidade, que fornece um fato forte para efeitos de memória a expulsão cajun da Acádia foi um fato traumatizante, e memórias traumáticas como elemento de identidade comum são extremamente fortes como arcabouço identitário de um grupo. Se ainda em solo norte-americano esta canção percorreu considerável percurso cultural até desembocar em Jambalaya (on the Bayou), sucesso de Hank Williams que alçou a melodia a nível mundial, no Brasil não foi diferente, onde sucessivas versões acarretaram em Álas folóra.

Nesse contexto, o conceito de hibridismo cultural, de Canclini (2011), atrelado aos processos de globalização e de fragmentação identitária das sociedades contemporâneas salientados por Hall (2002; 2011), contribuiu para questionar uma visão essencialista sobre a música pomerana, permitindo evidenciar hibridismos musicais entre a música alemã/ pomerana, a música gaúcha e a música nordestina no caso do Musical Boa Esperança.

Além disso, o conceito de memória cultural de Assmann (1995) contribui para elucidar os processos culturais empregados com sucesso tanto por Hank Williams quanto 
pelo Musical Boa Esperança no que tange o apelo étnico de suas versões de Le garçon negligent. Nas palavras do autor, "a memória cultural é complexa, plural, labiríntica, abrange uma multidão de diferentes memórias de pertença coletiva em diferentes tempos e espaços e retira destas tensões e contradições a sua própria dinâmica" (ASSMANN, 2004, p. 43). Enquanto Williams utilizou a melodia de uma canção cajun e manteve ofiddle como instrumento solista nos interlúdios para lograr êxito naquela comunidade com sua Jambalaya (on the Bayou) - apesar de sua roupagem country e de sua letra estereotipada da cultura em questão -, o Musical Boa Esperança pomeranizou a instrumentação com solos de instrumentos de sopro, elaborou uma letra na língua materna da comunidade de seu público-alvo e dotou-a de ethos camponês - embora tenha se utilizado de hibridismos entre a música alemã/pomerana e a música gaúcha e a música nordestina. Em ambos os casos, a herança cultural das comunidades em questão puderam ser compartilhadas e suas autoimagens transmitidas em meio a um contexto híbrido.

Quase um século separam Le garçon negligent e Álas folóra, porém, na moldura dos séculos XX e XXI, onde as transformações tecnológicas aceleraram os processos culturais, seu percurso reforça a visão contemporânea que questiona noções essencialistas acerca das identidades culturais e desconstrói entidades culturais fechadas. Acomplexidade dos fenômenos culturais híbridos, tais como os descritos acima, é exemplo do mosaico cultural de nossa contemporaneidade, do mundo interconectado em que vivemos.

\section{Referências}

ASSMANN, J.; CZAPLICKA, J. Collective Memory and Cultural Identity. New German Critique, n. 65, p. 125-133, spring/summer, 1995. . Religion und Kulturelles Gedächtnis. München: C. H. Beck, 2004.

KUHN, D. Projeto Pomerando: língua pomerana na Escola Germano Hübner. São Lourenço do Sul: Editora do autor, 2012.

KUHN, D; BEILKE, N. S. V. Projeto Pomerando II - língua pomerana na escola Germano Hübner: resgatando as raízes germânicas do pomerano. São Lourenço do Sul: Editora do autor, 2017.

BRASSEAUX, C. A. A New Acadia: The acadian migrations to south Louisiana, 17641803. Acadiensis, v. 15, n. 1, p. 123-132, 1985.

BURKE, P. Hibridismo cultural. São Leopoldo: Editora Unisinos, 2003. 
CANCLINI, N. G. Culturas Hibridas: estratégias para entrar e sair da modernidade. São Paulo: Editora da Universidade de São Paulo, 2011.

CARON, C. I. The Acadians. Ottawa: The Canadian Historical Association, 2015.

CERQUEIRA, F. V. Serra dos Tapes: mosaico de tradições étnicas e paisagens culturais. Anais Eletrônicos do IV SIMP, p. 872-874, 2010. Disponível em: $<$ https://simpufpel.files. wordpress.com/2010/09/mesa-serra-dos-tapes.pdf>. Acessado em: 08 mai. 2018.

COSTA, J. S. O Pescador de Arenques. Pelotas: EDUCAT, 2007.

ESCOTT, C. et al. Hank Williams: The Biography. Boston, MA: Little, Brown \& Co., 2004.

FERREIRA, M. L. M.; HEIDEN, R. Políticas patrimoniais e reinvenção do passado: os pomeranos de São Lourenço do Sul, Brasil. Cuadernos de Antropología Social, n. 30, p. 137-154, 2009.

HALL, S. Questions on cultural identity. Londres: Sage, 2002.

. A identidade cultural na pós-modernidade. 11 ${ }^{\mathrm{a}}$ ed. Rio de Janeiro: DP\&A, 2011.

HAMMES, E. L. São Lourenço do Sul: radiografia de um município - das origens ao ano 2000; vol. 1-4. São Leopoldo: Studio Zeus, 2010.

. A imigração alemã para São Lourenço do Sul: Da formação de sua Colônia aos primeiros anos após seu Sesquicentenário. São Leopoldo: Studio Zeus, 2014.

JORDAN, R. Folklore and Ethnicity: Some Theoretical Considerations in SPITZER, N., Louisiana Folklife: A Guide to the State. Baton Rouge: Louisiana Folklife Program, 48$54,1985$.

MCKERNAN, J. J. Acadia and the cajun culture landscape: adaption, accomodation authenticity. (Thesis) Interdepartmental Program in Liberal Arts, Louisiana State University, 2010.

PODEWILS, D. O. Colonização germânica: a colônia de São Lourenço e suas particularidades. 2011. 40 f. Monografia (Licenciatura em História) - Instituto de Ciências Humanas, Universidade Federal de Pelotas, Pelotas, 2011.

SALAMONI, G. (org.). Os pomeranos: Valores culturais da família de origem pomerana no Rio Grande do Sul - Pelotas e São Lourenço do Sul. Pelotas: Universitária, 1995.

SCHMIDT, A. A comida na cultura pomerana: simbolismo, identidade e sociabilidade. 2015. 190 f. Dissertação (Mestrado em Economia Doméstica). Departamento de Economia Doméstica, Universidade Federal de Viçosa, Viçosa, 2015.

SCHRÖDER, F. A imigração alemã para o sul do Brasil. 2a ed. São Leopoldo: Editora da Unisinos, co-edição com EDIPUCRS, 2003.

SHUKER, R. Popular Music: the Key concepts. 2a ed. New York: Routledge, 2005. 
SIGAL, A. Jambalaya by any other name. Petits Propos, n. 84, p. 101-119, 2007.

ULHÔA, M. T. et al. Música híbrida: Matrizes Culturais e a Interpretação da Música Brasileira. Anais Eletrônicos do XIII Encontro da ANPPOM, p. 348-354, 2001. Disponível em: <http://www4.unirio.br/mpb/ulhoatextos/Ulhoa_Aragao_Trotta_MusicaHibrida_ ANPPOM2001.pdf>. Acessado em: 08 mai. 2018.

WEBER, R.; BOSENBECKER, P. Disputas pela memória em São Lourenço do Sul: uma visão histórica de representações étnicas. Cadernos do CEOM, v. 23, n. 32, p. 347-369, jun. 2010.

WILlE, L. Pomeranos no sul do Rio Grande do Sul: trajetória, mitos, cultura. Canoas: Ed. ULBRA, 2011.

ZEHETMEYR, M. Uma amostra da realidade linguística dos pomeranos de duas regiões do Brasil. 2007. Monografia (Especialização em Leitura e Produção Textual) - Centro de Letras e Comunicação, Universidade Federal de Pelotas, Pelotas, 2007.

\section{Notas}

1 Esse artigo resulta de um aspecto de minha pesquisa de doutorado, intitulada Festa, dança e alegria: uma etnografia musical pomerana ao sul do sul do Brasil - São Lourenço do Sul/RS (2019), realizada no âmbito do Programa de Pós-Graduação em Memória e Patrimônio da Universidade Federal de Pelotas a partir do ano de 2015, sob orientação da musicóloga Isabel Porto Nogueira e do historiador e arqueólogo Fábio Vergara Cerqueira. As experiências de campo etnografadas, que sustentam o desenvolvimento de argumentos aqui expostos, foram realizadas durante o ano de 2016 por mim no contexto da referida tese.

2 Doutor em Memória Social e Patrimônio Cultural (UFPel/2019), Pelotas, Rio Grande do Sul, Brasil. danilokuhn@yahoo.com.br.

3 "Tudo perdido", em pomerano. Todas as palavras em pomerano neste artigo estão escritas segundo proposta simplificada de escrita (KUHN, 2012), haja vista que o dialeto, na região pesquisada, é utilizado apenas oralmente pela comunidade.

4 Na geografia política atual, a zona colonial situada sobre a Serra dos Tapes distribui-se entre os municípios de São Lourenço do Sul, Turuçu, Pelotas, Arroio do Padre, Canguçu, Capão do Leão e Morro Redondo, região sul do estado do Rio Grande do Sul, sul do Brasil (CERQUEIRA, 2010, p. 872).

5 Atual Szczecin, capital do estado polonês da Pomerânia ocidenal, principal cidade no noroeste do país; em alemão, Stettin.

6 Ver Zehetmeyr (2007) e Kuhn \& Beilke (2017).

7 A confirmação, de acordo com Schmidt (2015, p. 2), é um marco religioso na vida dos luteranos (equivalente à crisma no catolicismo) e se dá após o término de um período de estudos sobre a religião luterana, denominado ensino confirmatório. A maioria dos descendentes de pomeranos da Serra dos Tapes são luteranos.

8 Como são popularmente conhecidos na região os grupos de música germânica (HAMMES, 2010, v. 3, p. 54-55).

9 Correspondente, no alemão moderno, a "Alles verloren".

10 Processo esse altamente híbrido: uma fusão que passa pela re-interpretação da obra de um compositor do período Clássico (com toda sua semântica estético-musical contextualizada) ressemantizada através da linguagem do jazz realizada por um grupo musical cubano. Ou seja, o processo de reinterpretação de estéticas distintas passa pelo trabalho criativo de músicos com uma formação musical e cultural que passa por valores artísticos e de vida em Cuba.

11 Fenômenos transculturais, de acordo com Fernando Ortiz (1968), são processos nos quais ambas as partes da equação resultam modificadas, de onde emerge uma nova realidade, composta e complexa, que não se configura como uma aglomeração mecânica de caracteres, ou como um mosaico, mas como um fenômeno novo, original e independente (ORTIZ, 1968, p. 13). 
14 Filho de um primo do acordeonista Joe Falcon, responsável, junto a sua esposa, pela primeira gravação de música cajun na Luisiana, em 1928, Wade Falcon mantém um blog chamado Early Cajun Music - o qual se auto-intitula uma janela única para o mundo da música cajun entre 1928 e 1965, compilando histórias de sites, livros, artigos, notícias, anotações e entrevistas, sendo a maior parte do material oriunda da coleção pessoal do autor -, em post intitulado "Le garçon negligent" - Guidry Brothers [online]. Disponível em: http://earlycajunmusic.blogspot.com/2016/09/le-garcon-negligent-guidry-brothers.html. watch?v=afPBzMVnQGA.

16 Blog Early Cajun Music, em post intitulado "Big Texas" - Julius "Papa Cairo" Lamperez [online]. Disponível em: http://earlycajunmusic.blogspot.com/search?q=grand+texas.

17 Blog Early Cajun Music, em post intitulado "Le garçon negligent" - Guidry Brothers [online]. Disponível em: http://earlycajunmusic.blogspot.com/2016/09/le-garcon-negligent-guidry-brothers.html.

18 Blog Early Cajun Music, em post intitulado "Big Texas" - Julius "Papa Cairo" Lamperez [online]. Disponível em: http://earlycajunmusic.blogspot.com/search?q=grand+texas.

19 A partir da intenção de empreender minha pesquisa etnomusicológica, empenhei de antemão uma pré-etnografia musical pomerana realizada a partir do Projeto Pomerando, projeto relativo à língua e à cultura pomerana por mim desenvolvido na escola Germano Hübner, São Lourenço do Sul, desde 2010. Em 2014, o Pomerando recebeu apoio do Programa Federal Mais Cultura nas Escolas, o que lhe possibilitou a confecção de um CD de músicas populares e tradicionais, brincadeiras e contos tradicionais pomeranos. Parceira do projeto, a bandinha Musical Boa Esperança avalizou o pesquisador a empregar sua performance musical ao bandoneon em suas apresentações atreladas ao Pomerando, o que oportunizou a referida pré-etnografia.

20 «Fica amor», de Werner Niero, o Alemão do Forró [online]. Disponível em: https://www.youtube.com/ watch? $=$ ox $9 z G o i J c K g$.

21 «João Balaio», versão de João Bosco, interpretada pelo quarteto vocal Boca Livre [online]. Disponível em: https://www.youtube.com/watch? $\mathrm{v}=8 \mathrm{ADX}-6$ npgyA.

22 «ambalaya (on the Bayou)», Hank Williams [online]. Disponível em: https://www.youtube.com/ watch? $\mathrm{v}=\mathrm{Lq} 1 \mathrm{FBwLqgdQ}$.

23 «João Balaio», Mano Lima [online]. Disponível em: https://www.youtube.com/watch?v=1sfVZ1bpWMc.

24 Termo utilizado pelos integrantes do conjunto para se referirem às suas apresentações nos eventos coloniais.

25 «Álas folóra», Musical Boa Esperança [online]. Disponível em: https://www.youtube.com/ watch? $\mathrm{v}=$ SkJts3hCKgY.

26 Segundo informação de Pino, trombonista do Musical Boa Esperança, em conversa informal em 22 de agosto de 2017.

27 Segundo informação de Pino, trombonista do Musical Boa Esperança, em conversa informal em 22 de agosto de 2017.

28 No alemão moderno, "Alles verloren".

29 «Jambalaia do alemão», de Maurício Pflugseder, o Alemão de Lageode [online]. Disponível no internet

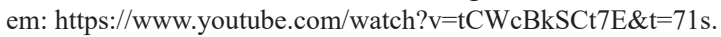

30 Em postagem em sua página no Facebook, por exemplo, o músico/humorista dá uma aula de hunsriqueano - enquanto o pomerano é um dialeto proveniente da região da Pomerânia, norte da Alemanha, o husriqueano provém do Hunsrück, sudoeste alemão - para seu público, disponibilizando uma pequena lista de substantivos. Ao final da postagem, ele escreve: "Se acaso alguem se lembrar de mais palavras, é só acrescentar e vamos dar uma aula de Alimón [alemão, em pronúncia que remete ao sotaque carregado de algumas pessoas de ascendência alemã], mostrando que conservamos nossa cultura em matéria de comunicação. Tangue chen ['obrigado']” [online]. Disponível na internet em: https://www.facebook.com/ oalemaodelageode/posts/1865943050098427.

31 De acordo com o próprio Pflugseder, em reportagem disponibilizada na internet, intitulada "Humorista gravará DVD na IV Forquetinha Expofest, em novembro/2013”, publicada em 12 de agosto de 2013 no site da Prefeitura Municipal de Forquetinha, estado do Rio Grande do Sul, Brasil. Em suas palavras: "Sou Alemão de origem e aprendemos a falar a lingua portuguesa só na adolescência. A gente não dizia Lajeado e sim Lageode" [online]. Disponível na internet em: http://www.forquetinha.rs.gov.br/ conteudo/0,3825_humorista-gravara-dvd-na-iv-forquetinha-expofest-em-novembro-2013. 
32 Em seu canal no YouTube, Maurício Pflugseder escreveu na descrição de sua canção: "Paródia do Jambalaia... O Alemão de Lageode" [online]. Disponível na internet em: https://www.youtube.com/ watch? $\mathrm{v}=\mathrm{tCWcBkSCt} 7 \mathrm{E} \& \mathrm{t}=71 \mathrm{~s}$.

33 «Jambalaia do alemão», de Maurício Pflugseder, o Alemão de Lageode, publicada em 01 de março de 2015 [online]. Disponível na internet em: https://www.youtube.com/watch? $\mathrm{v}=\mathrm{tCWcBkSCt7E \& t=71 \textrm {s } .}$

34 Publicada no YouTube em 01 de março de 2015 [online]. Disponível na internet em: https://www. youtube.com/watch? $\mathrm{v}=\mathrm{tCWcBkSCt} 7 \mathrm{E} \& \mathrm{t}=71 \mathrm{~s}$.

35 Arranjo para bandoneon criado pelo pesquisador/musicista durante sua etnografia musical pomerana em 2016.

36 Publicada no YouTube em 02 de junho de 2017 [online]. Disponível na internet em: https://www.youtube. $\mathrm{com} /$ watch? $\mathrm{v}=\mathrm{SkJts} 3 \mathrm{hCKgY}$. 